\title{
Manufacturing Process Capability and Specification Limits
}

\author{
Matti Mottonen*, Pekka Belt, Janne Harkonen, Harri Haapasalo and Pekka Kess
}

Department of Industrial Engineering and Management, University of Oulu, Finland

\begin{abstract}
In modern electronics, specifications for products have constantly been tightened due to performance competition. The processes for product development and manufacturing have been developed to meet the tighter specifications and quality requirements. The development of test methods and measurement devices have not been as fast, and as a consequence, the relative impact of measurement errors has increased. Traditionally, the measurement inaccuracies have been compensated by tightening the acceptance limits. This study concentrates on analysing, through simulation, how companies should minimise the failure costs by adjusting acceptance limits. The study shows, in contrast to the conventional thinking, that widening the acceptance limits makes business sense in some cases.
\end{abstract}

Keywords: Acceptance limits, process capability, gauge reproducibility and repeatability.

\section{INTRODUCTION}

Complexity of products and time-to-market demands, together with the decrease in physical dimensions in electronics cause pressures for manufacturing processes. Increased complexity has added to the number of tests to be conducted, making testing ever complicated, time-consuming, and costly. The accuracy of measurements systems, process variation, failure costs and adjusting acceptance limits are vital parameters for optimising costs in electronics manufacturing.

Specification limits describe requirements for products, while acceptance limits are the actual decisive factors in manufacturing. Conventional approach has been tightening the acceptance limits, in order to assure quality [1-4]. This study analyses whether it is worthwhile from the business perspective to consider the opposite, and widen the acceptance limits.

Traditionally, variation of manufacturing processes has been dissected, in both industry and in the literature, as described in Fig. (1A) [5]. Process variation has been relatively significant compared to the specification limits, and thus the dominant factor for assessing processes. The measurement error has been added into Fig. (1B) to illustrate the impact of inaccuracy of measurement systems. The measurement error has typically been small compared to process variation.

Constant product performance requirements have lead to ever tighter specifications in modern high technology sector [6]. The improvement in design of manufacturing processes has been even faster. A typical parameter variation curve is narrow in capable processes, as shown in Fig. (1C). When processes are capable the measurement inaccuracy has more relative importance and has therefore become a more dominant factor, as shown in Fig. (1D) [7].

*Address correspondence to this author at the Department of Industrial Engineering and Management, University of Oulu, Finland; Tel: +358-85532931; Fax: +358-8-5532904; E-mail: matti.mottonen@oulu.fi

1874-1525/08
Measurement errors are unavoidable, and thus must be addressed [5]. This study discusses the optimal placement of acceptance limits, based on the relation of process capability and measurement error of test systems in modern capable high volume electronics manufacturing. Controlling acceptance limits is based on risk assessment and on economic considerations. This paper considers, through simulation, the economic impact of faults in products received by customers, in relation to false alarms, caused by the inaccuracy of measurement systems. These costs are compared to each other in order to find an ideal economic balance. The minimisation of quality costs is studied by analysing the feasibility of widening or tightening the acceptance limits.

The empirical part of the study contains two stages. The first stage utilises real industrial data for analysing the current status of both, process capabilities, and measurement system inaccuracies. The second stage, the key of this study, simulates the economic impact of adjusting acceptance limits, and is conducted for a large set of values of process variation, measurement system variation, and internal \& external failure costs. All the parameters are company specific, thus when the values are know, the optimal placement of acceptance limits can be calculated. This study clarifies the basis, and the principles for this type of calculations.

The essence of the previous paragraphs can be condensed into the following research questions:

RQ1. Is it economically feasible to widen the acceptance limits in some cases?

RQ2. What are the circumstances, where widening makes good business sense, and how can the required calculations be made in principle?

\section{THEORY}

Generally, quality costs can be divided into conformance and non-conformance costs. Conformance costs cover both prevention and appraisal, while non-conformance costs include internal and external failure costs [8-10]. 

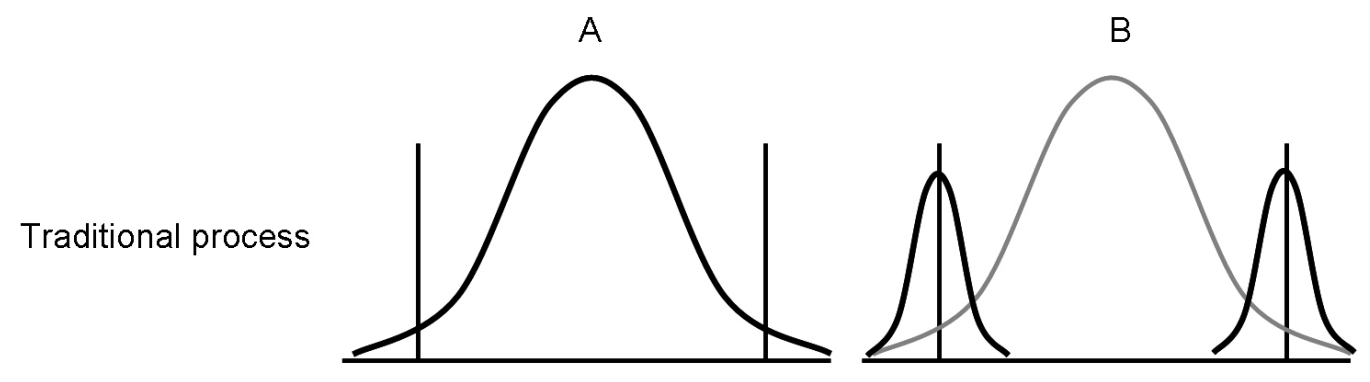

C

$\mathrm{D}$

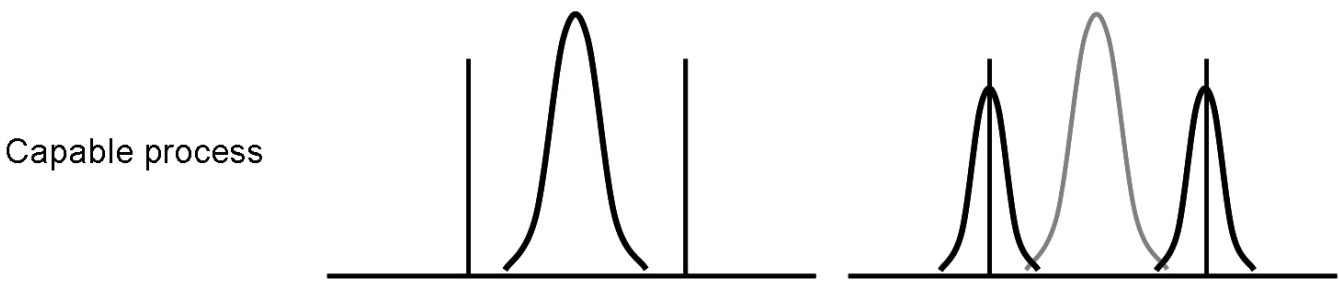

Fig. (1). Process Variation and Inaccuracy of Measurement System in Traditional and Capable Processes.

Product variation is a significant factor affecting product quality and causing costs. Therefore, it is sensible to minimise product variation in manufacturing. There are numerous methods of minimising variation (prevention), e.g. statistical process control (SPC) tools $[11,12]$, six sigma methods [13-15], Taguchi's Design of experiments [16, 17]. Also, the development and purchase of different test methods and equipment are economically feasible (appraisal). Test equipment investments require, however, economic justification [5].

For clarification, this study does not cover the issues of minimising product variation in manufacturing, nor improving the accuracy of measurement and test systems. On the contrary, they are merely considered as a starting point. This study concentrates on mathematically analysing, how companies should minimise the failure costs by adjusting acceptance limits.

The key terminology for understanding this research includes the concepts of process capability indices (PCI), Type I \& Type II errors, guardbands, and gauge reliability and reproducibility (GR\&R).

The PCIs are used to numerically describe the capability of a manufacturing process to produce items fulfilling the quality requirement preset [18]. Type I \& Type II errors are false judgements on product quality due to the inaccuracy of a measurement system. Type I error occurs when a good product fails a test (internal failure costs), and a Type II error occurs when a defective product is passed on to a customer (external failure costs) [19]. Product specific ratios of these internal and external failure costs are used later in this study when calculating the economic impacts.

The concept of guardbands represents the methods to tackle the inaccuracy of a measurement system by tightening the acceptance limits in order to secure product quality seen by customers, while attempting to minimise the quality costs. There are numerous studies on guardbands and how to specify them optimally [1-5]. These studies, however, examine guardbands from the viewpoint of quality assurance, where the special emphasis is not on minimising the quality costs.

GR\&R is a methodology to describe the capability of a measurement system [20-22]. The studies on GR\&R, however, do not discuss what to do, or how to react, if the measurement system is not particularly capable.

This paper considers the above-mentioned issues in a new manner. The aim is to utilise data on process capability and data on the inaccuracy of a measurement system (GR\&R) to control the acceptance limits, so that the expenses caused by faulty products will be optimally minimised.

\section{PROCESS CAPABILITY}

The purpose of manufacturing is to 'duplicate' the products designed by $R \& D$. In mass production thousands and millions of products are manufactured. Nevertheless, manufacturing processes are never stable enough for every product to be an ideal replica of the desired product [23]. Therefore, different methods must be utilised to compensate these deficiencies.

Process capability indices (PCIs) are used in the manufacturing industry to provide numerical measures on whether a process is capable of producing items within the predetermined specification limits [24]. The modern high-volume industry has been forced to develop its process capability to ever higher levels to meet the high-level demands set for the products. As a consequence process deviation is narrow in capable processes. For example, the process in Fig. (1C) is more capable than the one in Fig. (1A). 
The most common PCIs include $\mathbf{C}_{\mathbf{p}}$ [25], and $\mathbf{C}_{\mathbf{p k}}$ [26]; see equations $1 \& 2$.

$$
\begin{aligned}
& C_{p}=\frac{U S L-L S L}{6 \sigma}, \\
& C_{p k}=\frac{\min \{U S L-\mu, \mu-L S L\}}{3 \sigma},
\end{aligned}
$$

where $\mu$ is the process mean, USL is the upper specification limit, LSL is the lower specification limit and $\sigma$ is the process standard deviation.

The real values of $\mu$ and $\sigma$ in a process remain unknown, because in practise values are calculated from sample data. Instead, an average, $\overline{\mathrm{X}}$ (see equation (3)), and standard deviation, $\mathrm{S}$ of collected data are used (see equation (4)) to calculate $\mathrm{Cp}$ and $\mathrm{Cpk}$. The data used for calculating $\mathrm{Cp}$ and Cpk are based on samples. Relatively large samples are required the values to be reliable (100 to 200, at least) [27]. There are several studies on calculating $\mathrm{Cp}$ and $\mathrm{Cpk}$ using sample data, see e.g. [28, 29].

$$
\begin{aligned}
& \bar{X}=\frac{\sum_{i=1}^{n} X_{i}}{n}, \\
& S=\sqrt{\frac{\sum_{i=1}^{n}\left(X_{i}-\bar{X}\right)^{2}}{n-1}} .
\end{aligned}
$$

The use of $\mathrm{C}_{\mathrm{p}}$ and $\mathrm{C}_{\mathrm{pk}}$ assumes the process output to be normally distributed, process variation to be symmetrical and the target $(\mathrm{T})$ to be in the centre of the specification tolerance $[23,30,31]$. All of these requirements must be fulfilled for these indices to be fully utilised [27]. This study, however, assumes $\mathrm{Cp}$ and $\mathrm{Cpk}$ to be reliably calculated. Deeper analysis of their calculations is outside the scope of the study.

Electronic products, like any other products, are manufactured using materials and processes that are inherently variable while the manufacturing process variability is usually approximated by normal distribution, see e.g. [32]. The normal distribution is characterised by the bell-shaped and symmetrical Gaussian curve [33]. Although, there are situations where the non-Gaussian distributions are possible, this study assumes, for simplification, that processes and measurement errors are normally distributed.

\section{MEASUREMENT ERRORS}

Tests provide information not only on individual characteristics of products but also on processes and the instrument used for measuring [1]. The accuracy of measurement systems is crucial when assessing product quality. The inaccuracy of test equipment is a relatively common problem, in the electronics industry, causing expenditure [34]. These expenditures are caused by phantom defects, i.e. there is nothing wrong with the actual product, but the fault is in the system used for testing.

Variability in measurements can result in false conclusions on product quality. Measurement errors are unavoidable due to the variations in operators and/or devices regardless of how well measurement procedures are designed or maintained. Inaccuracies in manufacturing testing cause two different types of errors, both of which result in extra costs and lower manufacturing quality. As mentioned before, a Type I error occurs when a good product is failed, and a Type II error occurs when a defective product is passed on to a customer. [5, 19]. Fig. (2) describes all the four different test cases including the two correct assessments (test cases 1 $\& 2)$.

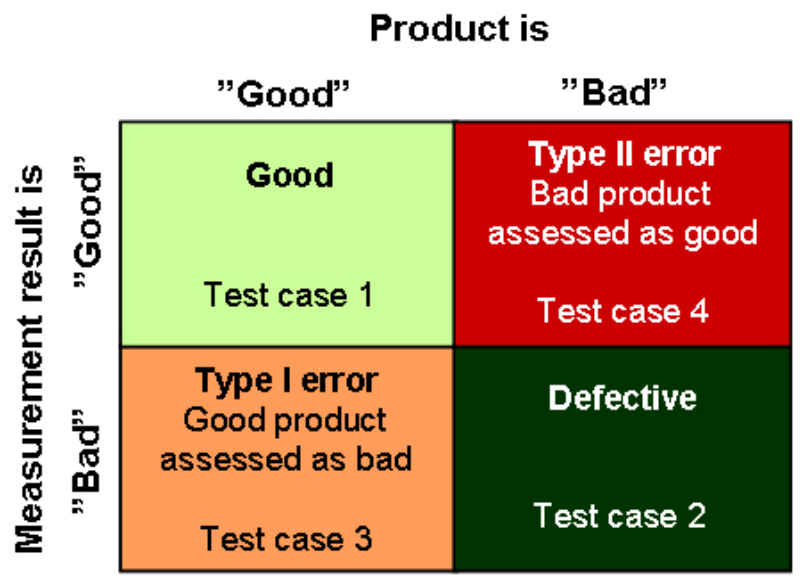

Fig. (2). Four test cases.

There are several ways to control and minimise measurement errors. The most immediate approach to control measurement errors is to buy more precise and expensive measurement equipment and hire/train personnel that are more competent. However there are technical and economic limits [5].

\section{GAUGE RELIABILITY AND REPRODUCIBILITY}

There are five main concepts that are used to describe the performance of a measurement system: accuracy, repeatability, reproducibility, stability and linearity, see [35]. Even though the absolute accuracy of measurement systems is important, reliability and repeatability/reproducibility are even more important. When calculating the process capability it is also important to assure that the measurement equipment is capable enough. The variation of a measurement system should be narrow compared to the preset specifications [23].

The variability of measurement systems is also known as gauge (or gage) variability. Most of the measurement errors can be measured and quantified through gauge reliability and reproducibility (GR\&R) methodology, which is a commonly known concept (e.g. in Six Sigma). Measurement systems include test equipment and operators. Variability of measurement systems should be small in relation to both process variability and specification limits. The purpose of conducting the GR\&R study is to quantify measurement error and to reduce the measurement system variation if it is excessive. $\mathrm{Hu}$ et al. [36] note that when categorising products as good and bad the GR\&R should be compared to the specification area. On the other hand, if the process itself is to be developed the GR\&R should be compared to the total variation. A common rule of thumb is that the measurement variability should be no greater than $10 \%$ of the smaller, of either the process variability or specification limits [32,37]. 
It is common in scientific studies to analyse processes with Cp or Cpk values between 1 (3 sigma) and 2 (6 sigma). On the other hand some researchers argue that the GR\&R target of $10 \%$ is too demanding, see e.g. [38]. The studies typically analyse single tests. In the electronics sector the products are, however, complicated comprising of numerous components and features, and are tested through a high number of tests. As a consequence, more is required from every individual test and to keep the product quality high.

In a typical GR\&R study, several operators each measure a selected set of items more than once. In the GR\&R, repeatability is a measure of the consistency of readings of the same part for a single operator and reproducibility is a measure of variation in average measurements, when different operators (appraisers) are taking many measurements of the same part. GR\&R methodology is based on a controlled and defined measurement procedure. More in depth information on GR\&R methodology can be found for example in [32, 37].

\section{REACTING TO MEASUREMENT ERRORS}

Adjusting acceptance limits is crucial when attempting to improve process performance [30]. Acceptance limits are traditionally tightened to reduce Type II errors and their adverse effect on customer satisfaction. The difference between tightened acceptance and original specification is called a guardband, which was pioneered by [39, 40]. However, for a given instrumentation inaccuracy, a reduction in Type II errors causes an increase in the Type I errors and in associated waste: scrap and rework. Guardbands are often used in manufacturing testing when instrumentation inaccuracies are present, in order to protect against the error of inadvertently certifying a defective product as good. Unfortunately, guardbands also increase the amount of good products that are erroneously failed in testing $[5,19]$.

\section{THE SIMULATION PROCESS}

In this study, the value of testing is based on the minimisation and management of risks. Risk is defined as the probability of an event multiplied by its impact (loss), see e.g. [41].

Combining quality costing and risk based approach enables economic optimisation. There can be four different test cases as presented earlier in Fig. (2). (1) a good product is assessed as good, (2) a bad product is assessed as bad, (3) a good product is assessed as bad (Type I error), and (4) a bad product is assessed as good (Type II error). By analysing the probability of each test case and multiplying it by the costs caused by it, the total costs are calculated.

The probabilities of the test cases are calculated by using the process variation ( $\mathrm{Cpk}$ ) and the variation of the measurement system. In practice, the latter can be obtained from the GR\&R analysis. In this study both the process and the inaccuracy of the measurement system are assumed to be normally distributed.

The probability for each test case (1-4) is calculated by multiplying normal distribution of the particular test parameter by the normal distribution of the measurement system. Due to the fact that the functions of normal distributions cannot be integrated [33], numerical methods must be used for the calculations. In this study, the probabilities for the test cases are calculated as follows:

1. Normal distributed test data have been divided into 100 even segments from $-6 \sigma$ to $+6 \sigma$.

2. The area of normal distribution falling within each segment is calculated by using normal distribution functions.

3. The peak of variation on normally distributed measurement system and the centre of each segment is placed on top of each other.

4. It is then checked whether the central point of each segment is inside the specification limits. If the central point is inside the given limits, the cases $1 \& 3$ are valid, and if the central point is outside the limits, the cases $2 \& 4$ are valid.

5. The variation of the measurement system within each segment will always fall partially inside and outside the specification limits. The shares for these two are calculated for each segment separately using normal distribution functions.

6. The shares obtained in 5, are multiplied by the corresponding shares of test data for each segment to obtain the probabilities of the test cases.

7. The results for each segment are summed to get the total probabilities for each test case for the normally distributed area.

After calculating the probabilities for each test case (1-4), the quality costs can be estimated for each distinct test case. This can be done by calculating the quality related expenses for each test case by multiplying the probability of the test case with related internal and external failure costs.

Obviously, the test case 1 (good products) does not cause any additional expenses. The test cases 2 and 3 cause additional fault-finding and repair costs (internal failure costs). The test case 4 causes expenses on additional fault-finding, repair, and on customer dissatisfaction (external failure costs).

The costs for the test cases 1 to 4 were summed up to obtain the total failure costs. Eventually, conclusions were made on how to adjust the acceptance limits in different situations. This was done by calculating the total failure costs by using different values for the analysed parameters (process capability, and inaccuracy of the measurement system and acceptance limits).

\section{RESULTS}

The empirical part of the study was conducted in two stages. The intention of the first stage was to confirm the relevancy of considering widening the acceptance limits. The second stage, the key of this study, simulates the economic impact of adjusting acceptance limits, and is conducted for a large set of values of process variation, measurement system variation, and internal \& external failure costs.

\section{ELECTRONICS INDUSTRY PROCESS DATA}

An initial analysis was conducted in this study to reveal the current state of manufacturing process capability and 
accuracy of measurements systems in the modern electronics industry. The raw data (obtained from the industry) included the results from 238 different tests, the sample size being 108. The data also included GR\&R results for the tests. The $\mathrm{Cp}$ values for the tests were calculated and analysed based on this data (see Table 1). The Table 1 shows that in most cases the $\mathrm{Cp}$ values are higher than 2.00 (96.2\% of the tests), which mean very high quality (beyond six sigma). Only in $3.8 \%$ of the tests the $\mathrm{Cp}$ value is less than 2 , which is at the six sigma level. This means that the product development process is in a very good shape at least as far as these parameters are concerned.

Table 1. Process Capability of Modern Industry

\begin{tabular}{|c|c|c|c|c|c|}
\hline $\mathrm{Cp}$ & $0-1$ & $1-2$ & $2-5$ & $5-10$ & $>10$ \\
\hline $\begin{array}{c}\text { Number of } \\
\text { tests }\end{array}$ & 0 & 9 & 46 & 91 & 92 \\
\hline
\end{tabular}

The Table 2 presents the relationship between GR\&R and specification limits. It can be noted that the GR\&R values for the measurement equipment are mainly good. Only in two tests the GR\&R/SL is over $10 \%$, which is, in the literature, considered as the threshold value for good systems.

Table 2. Measurement Variation Compared to Specification Limits

\begin{tabular}{|c|c|c|c|c|}
\hline & \multicolumn{4}{|c|}{ Variation of measurement system / spec limits } \\
& \multicolumn{4}{|c|}{ (GR\&R/SL) } \\
\hline \hline & $0-5 \%$ & $5-10 \%$ & $10-15 \%$ & $>15 \%$ \\
\hline Number of tests & 220 & 16 & 2 & 0 \\
\hline
\end{tabular}

The Table 3 shows the variation of GR\&R compared to the variation of the test results. The variation of the measurement system is significant compared to product variation.

Table 3. Measurement Variation Compared to Product Variation

\begin{tabular}{|c|c|c|c|c|}
\hline & \multicolumn{4}{|c|}{$\begin{array}{l}\text { Variation of measurement system / product variation } \\
\qquad(\text { GR\&R/ })\end{array}$} \\
\hline & $0-10 \%$ & $10-30 \%$ & $30-100 \%$ & $>100 \%$ \\
\hline $\begin{array}{c}\text { Number of } \\
\text { tests }\end{array}$ & 0 & 0 & 150 & 88 \\
\hline
\end{tabular}

These results (Tables $\mathbf{1}$ to $\mathbf{3}$ ) support the claim presented in Fig. (1D), on the situation, where the processes in current electronics companies are extremely capable, and that the inaccuracy of the measurement systems is significant in relation to the process variation. This justifies the simulations of the second stage.

\section{SIMULATION RESULTS}

There are three parameters that affect the definition of acceptance limits:

1. process capability

2. variation of the measurement system

3 . the relationship between defect costs (external quality costs) and repair costs (internal quality costs)

This study analyses adjusting acceptance limits by using four different internal and external failure cost ratios $(1: 10$, $1: 24,1: 50$ and 1:100). The 1:24 cost ratio was selected based on input of a case company. The other ratios are for understanding how sensitive this ratio is. The ratio can be different, and it is vital for a business to understand the situation specific to them.

The question on, whether to make acceptance limits tighter or wider has been dissected in this study by analysing the total failure costs by increasing, or decreasing, the specification limits by $10 \%$. Ten percent was selected for an obvious simplicity.

Table 4 presents the implications of increasing, or decreasing, the acceptance limits in comparison to the failure costs. The example presented in Table 4 has Cpk of 1.5 and GR\&R/SL of $15 \%$ and 1:24 cost ratio. The costs for the test cases 2-3 have been calculated with the coefficient 1 and for the test case 4 with the coefficient 24 . Table 4 clearly shows how, in this particular case, widening the limits would make sense from the economic viewpoint.

As an example of interpreting Table 4: should one million products be manufactured, each requiring one hundred tests, internal cost being $1 \$$ per failure, and external cost being $24 \$$ per failure, ten percent wider acceptance limits would result in savings of $=(0.007-0.003) * 100 * 1000000=$ $400000 \$$.

Tables 5 through 8 present the results of this study. The tables analyse how the acceptance limits should be positioned, in order to minimise the failure costs. The analysis covers process capability values $1-2$, and measurement system variation in relation to specification limits (GR\&R/SL) in the range of $0.1 \%-20 \%$. For each $\mathrm{Cpk}$ and GR\&R/SL combination, all three possibilities of keeping the acceptance limits as they are, widening, or making them tighter are considered. This is done on the basis of the total costs by selecting the most favourable option. This study presents four different internal/external failure cost ratios: 1:10 (Table 5), 1:24 (Table 6), 1:50 (Table 7), and 1:100 (Table 8).

Tables 5-8 clearly point out how, in many situations, widening the acceptance limits is economically feasible. It can be seen how, with well-specified products, in capable manufacturing processes, it would be sensible to consider widening the acceptance limits to minimise the total costs. The more inaccurate the measurement system is the less capable processes allow widening of the limits.

It can be seen out of the Tables $\mathbf{5}$ through $\mathbf{8}$ how internal/external cost ratios affect the adjustment of acceptance limits. Obviously, the smaller the difference between internal and external failure costs is, the more economical it is to 
Table 4. Numerical Example of Calculations (Cpk 1.5, GR\&R/SL 15\%, Cost Ratio 1:24)

\begin{tabular}{|c|c|c|c|c|c|}
\hline & $\begin{array}{c}\text { OK } \\
\text { (Test case } 1)\end{array}$ & $\begin{array}{c}\text { Fail } \\
\text { (Test case 2) }\end{array}$ & $\begin{array}{c}\text { Type I } \\
\text { Test case } 3\end{array}$ & $\begin{array}{c}\text { Type II } \\
\text { Test case } 4\end{array}$ & Total \\
\hline \multicolumn{6}{|l|}{ Original } \\
\hline$\%$ (probability of occurrence) & $99.26 \%$ & $0.0003 \%$ & $0.74 \%$ & $0.0002 \%$ & $100 \%$ \\
\hline Cost & 0 & 0.000003 & 0.007383 & 0.000052 & 0.007 \\
\hline \multicolumn{6}{|l|}{$10 \%$ tighter } \\
\hline$\%$ (probability of occurrence) & $98.41 \%$ & $0.0004 \%$ & $1.59 \%$ & $0.0002 \%$ & $100 \%$ \\
\hline Cost & 0 & 0.000004 & 0.015922 & 0.000037 & 0.016 \\
\hline \multicolumn{6}{|l|}{$10 \%$ wider } \\
\hline$\%$ (probability of occurrence) & $99.68 \%$ & $0.0000 \%$ & $0.32 \%$ & $0.0005 \%$ & $100 \%$ \\
\hline Cost & 0 & 0.000000 & 0.003209 & 0.000111 & 0.003 \\
\hline
\end{tabular}

Table 5. How the Acceptance Limits Should Be Adjusted When Internal External Cost Ratio Is 1:10

\begin{tabular}{|c|c|c|c|c|c|c|c|}
\hline \multirow[b]{2}{*}{ Cpk } & \multicolumn{7}{|c|}{ Variation of measurement system /spec limits (GR\&R/SL) } \\
\hline & $0.1 \%$ & $1 \%$ & $3 \%$ & $5 \%$ & $10 \%$ & $15 \%$ & $20 \%$ \\
\hline 1 & $=$ & $=$ & $=$ & $=$ & $=$ & $>$ & $>$ \\
\hline 1.25 & $=$ & $=$ & $=$ & $=$ & $>$ & $>$ & $>$ \\
\hline 1.5 & $=$ & $=$ & $=$ & $>$ & $>$ & $>$ & $>$ \\
\hline 1.75 & $=$ & $=$ & $=$ & $>$ & $>$ & $>$ & $>$ \\
\hline 2 & $>$ & $>$ & $>$ & $>$ & $>$ & $>$ & $>$ \\
\hline
\end{tabular}

Table 6. How the Acceptance Limits Should Be Adjusted When Internal External Cost Ratio Is $\underline{1: 24}$

\begin{tabular}{|c|c|c|c|c|c|c|c|}
\hline \multirow[b]{2}{*}{ Cpk } & \multicolumn{7}{|c|}{ Variation of measurement system /spec limits (GR\&R/SL) } \\
\hline & $0.1 \%$ & $1 \%$ & $3 \%$ & $5 \%$ & $10 \%$ & $15 \%$ & $20 \%$ \\
\hline 1 & $=$ & $<$ & $<$ & $<$ & $=$ & $=$ & $=$ \\
\hline 1,25 & $=$ & $<$ & $<$ & $=$ & $=$ & $>$ & $>$ \\
\hline 1,5 & $=$ & $=$ & $=$ & $=$ & $>$ & $>$ & $>$ \\
\hline 1,75 & $=$ & $=$ & $=$ & $>$ & $>$ & $>$ & $>$ \\
\hline 2 & $>$ & $>$ & $>$ & $>$ & $>$ & $>$ & $>$ \\
\hline
\end{tabular}


Table 7. How the Acceptance Limits Should Be Adjusted When Internal External Cost Ratio Is 1:50

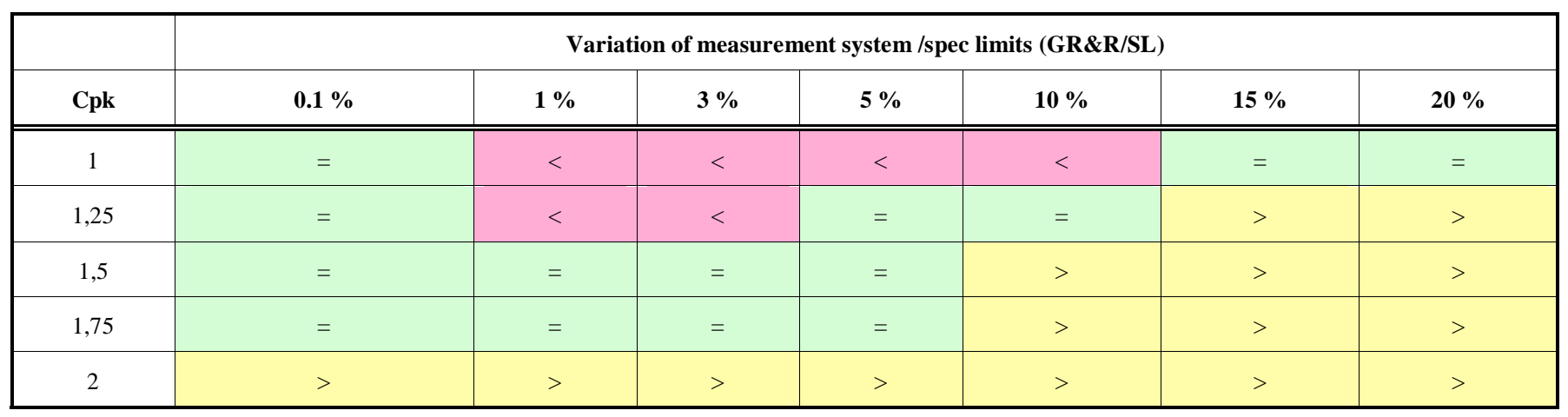

Table 8. How the Acceptance Limits Should Be Adjusted When Internal External Cost Ratio Is $\underline{1: 100}$

\begin{tabular}{|c|c|c|c|c|c|c|c|}
\hline \multirow[b]{2}{*}{ Cpk } & \multicolumn{7}{|c|}{ Variation of measurement system /spec limits (GR\&R/SL) } \\
\hline & $0.1 \%$ & $1 \%$ & $3 \%$ & $5 \%$ & $10 \%$ & $15 \%$ & $20 \%$ \\
\hline 1 & $=$ & $<$ & $<$ & $<$ & $<$ & $<$ & $=$ \\
\hline 1,25 & $=$ & $<$ & $<$ & $<$ & $=$ & $=$ & $>$ \\
\hline 1,5 & $=$ & $=$ & $<$ & $=$ & $=$ & $>$ & $>$ \\
\hline 1,75 & $=$ & $=$ & $=$ & $=$ & $>$ & $>$ & $>$ \\
\hline 2 & $>$ & $>$ & $>$ & $>$ & $>$ & $>$ & $>$ \\
\hline
\end{tabular}

$<=$ make acceptance limits tighter

$==$ keep acceptance limits as they are

$>=$ make acceptance limits wider

widen the acceptance limits. And vice versa, the greater the difference is, the more sensible it is to tighten the limits.

\section{CONCLUSION}

One important question management faces in electronics manufacturing is; when and how should the acceptance limits be adjusted? The common way of thinking is to make the limits tighter in order to secure the desired quality. This study supports this practise only when the manufacturing process is not particularly capable and when the measurement inaccuracy compared to the specification limits is less significant $(<5 \%)$.

If the manufacturing process is at the six sigma level (Cpk is 2 or better), tightening of the acceptance limits causes extra costs due to phantom defects. In capable processes, the acceptance limits should be widened instead of tightened. Widening the limits is also justified in processes with lower capabilities if the accuracy of the measurement equipment is relatively poor.

This study confirms that the manufacturing processes in successful electronics companies are very capable (way beyond six sigma) and that the inaccuracy of the measurement systems is reasonable. The companies have noticed how phantom defects are a noteworthy problem. In order to tackle this problem companies should abandon their old mindset of always tightening acceptance limits. These tactics do not function in all situations, in modern capable processes of electronics manufacturing. The decisions should, and can be made on economic basis.

In order to adjust acceptance limits on economic basis, the probabilities for different test cases must be calculated. The values, or good estimates, over the following parameters are required: Process capability (Cpk), measurement systems variation (GR\&R), and the ratio of internal and external failure costs. A procedure to execute the calculations is presented in this paper.

The interesting findings of this study require further research, especially from other business sectors. Also, it would be beneficial to clarify how much the acceptance limits should be moved.

\section{ACKNOWLEDGEMENTS}

This research has been supported by the National Technology Agency (Tekes), Nokia, Nokia-Siemens Networks, Elektrobit Group, Agilent Technologies, Polar Electro, Nethawk, Nokia Foundation, Jenni and Antti Wihuri Foundation, and Riitta and Jorma Takanen Foundation.

\section{REFERENCES}

[1] Y. M. Chou and K. S. Chen, "Determination of Optimal Measurement Guardbands," Quality \& Quantitative Management, vol. 2, pp. 65-75, 2005.

[2] M. Wang, R. Jiang, J. W. Hsia, C. Wang and J. Chen, "Guardband determination for the detection of off-state and junction leakages in DRAM testing," Test Symposium, Proceedings.10th Asian, 2001, pp. 151-156. 
[3] W. Albers, W. C. M. Kallenberg and G. D. Otten, "Setting test limits under prescribed consumer loss," Metrika, vol. 41, pp. 163$181,1994$.

[4] D. McCarville and D. Montgomery, "Optimal guard bands for gauges in series," Quality Engineering, vol. 9, pp. 167-177, 1996.

[5] Y. J. Kim, B. R. Cho and N. K. Kim, "Economic design of inspection procedures using guard band when measurement errors are present,"Applied Mathematical Modeling, vol. 31, pp. 805-816, 2007.

[6] J. Dantan, J. Bruyere, C. Baudouin and L. Mathieu, "Geometrical Specification Model for Gear-Expression, Metrology and Analysis," CIRP Annals-Manufacturing Technology, vol. 56, pp. 517520,2007

[7] F. W. Kear, Statistical Process Control in Manufacturing Practice. CRC Press, 1998, pp. 240.

[8] A. V. Feigenbaum, Total Quality Control: Engineering and Management. New York: McGraw-Hill New York, pp. 627, 1961

[9] J. Michalska, "Quality costs in the production process," Journal of Achievements in Materials and Manufacturing Engineering, vol. 17, pp. 425-428, 2006.

[10] J. S. Oakland, TQM: Text with Cases., 2nd ed. Oxford: Butterworth-Heinemann, 2000, pp. 380.

[11] W. Shewhart, Statistical Method from the Viewpoint of Quality Control. Courier Dover Publications, 1986.

[12] A. R. Motorcu and A. Güllü, "Statistical process control in machining, a case study for machine tool capability and process capability," Materials and Design, vol. 27, pp. 364-372, 2006.

[13] G. Hahn, W. J. Hill, R. Hoerl and S. Zinkgraf, "The Impact of Six Sigma Improvement-A Glimpse into the Future of Statistics." The American Statistician, vol. 53, pp. 208-215, 1999.

[14] M. Harry and R. Schroeder, Six Sigma: The Breakthrough Management Strategy Revolutionizing the World's Top Corporations. Currency, New York, 2000,

[15] Y. H. Kwak and F. T. Anbari, "Benefits, obstacles, and future of six sigma approach," Technovation, vol. 26, pp. 708-715, 2006

[16] G. Taguchi, Introduction to Quality Engineering. Asian Productivity Organization, Tokyo, 1986.

[17] J. Antony, D. Perry, C. Wang and M. Kumar, "An application of Taguchi method of experimental design for new product design and development process," Assembly Automation, vol. 26, pp. 18-24, 2006.

[18] K. T. Yu, S. H. Sheu and K. S. Chen, "Testing multi-characteristic product capability indices," The International Journal of Advanced Manufacturing Technology, vol. 34, pp. 421-429, 2007.

[19] R. H. Williams and C. F. Hawkins, "The effect of guardbands on errors in production testing," in European Test Conference. Proceedings of ETC 93., Third, 1993, pp. 2-7.

[20] G. A. Larsen, "Measurement System Analysis: The Usual Metrics Can Be Noninformative," Quality Engineering, vol. 15, pp. 293298,2002
[21] G. A. Larsen, "Measurement System Analysis in a Production Environment with Multiple Test Parameters," Quality Engineering, vol. 16, pp. 297-306, 2003.

[22] D. Mader, J. Prins and R. Lampe, "The economic impact of measurement error," Quality Engineering, vol. 11, pp. 563-574, 1999.

[23] M. Deleryd, "On the gap between theory and practice of process capability studies," International Journal of Quality \& Reliability Management, vol. 15, pp. 178-191, 1998.

[24] K. S. Chen, W. L. Pearn and P. C. Lin, "Capability measures for processes with multiple characteristics," Quality and Reliability Engineering International, vol. 19, pp. 101-110, 2003.

[25] J. M. Juran, Quality Control Handbook, 3rd. ed. New York: Mcgraw-Hill, 1974.

[26] V. E. Kane, "Process capability indices," Journal of Quality Technology, vol. 18, pp. 41-52, 1986

[27] B. H. Gunter, "The Use and Abuse of Cpk". Qualification Program, vol. 22, pp. 108-109, 1989.

[28] W. L. Pearn and C. H. Chen, "A practical implementation of the process capability index C pk," Quality Engineering, vol. 9, pp. 721-737, 1997.

[29] H. C. Lin, "Using normal approximation on testing and determining sample size for Cpk," J. Chin. Inst. Ind. Eng., vol. 23, pp. 1-11, 2006

[30] J. J. Flaig, "Process Capability Optimization," Quality Engineering, vol. 15, pp. 233-242, 2002.

[31] W. Pearn, P. Lin and K. Chen, "Estimating process capability index C"pmk for asymmetric tolerances: Distributional properties," Metrika, vol. 54, pp. 261-279, 2002.

[32] S. G. Shina, Six Sigma for Electronics Design and Manufacturing. New York: McGraw-Hill Professional, 2002, pp. 363.

[33] E. Kreyszig, Advanced Engineering Mathematics. 8th ed. New York: John Wiley \& Sons Inc., 1999, pp. 865

[34] P. Belt, J. Harkonen, M. Mottonen, P. Kess and H. Haapasalo, "Improving the efficiency of verification and validation," International Journal of Services and Standards, vol. 4, pp. 150-166, 2008.

[35] Measurement Systems Analysis Reference Manual., 2nd ed. Chrysler Corp., Ford Motor Corp., General Motors Corp., 1995.

[36] M. Hu, B. Barth and R. Sears, "Leveraging Six Sigma disciplines to drive improvement," International Journal of Six Sigma and Competitive Advantage, vol. 1, pp. 121-133, 2005.

[37] F. W. Breyfogle, Implementing Six Sigma: Smarter Solutions ${ }^{\circledR}$ using Statistical Methods, 2nd ed. New Jersey: Wiley, 2003.

[38] K. R. Jaynes, "Reviewing Gage R\&R," Manufacturing Engineering, vol. 118, pp. 12-12, 1997.

[39] A. R. Eagle, "A Method for Handling Errors in Testing and Measuring," Industrial Quality Control, vol. 10, pp. 10-15, 1954

[40] F. Grubbs and H. Coon, "On setting test limits relative to specification limits," Industrial Quality Control, vol. 10, pp. 15-20, 1954.

[41] B. W. Boehm, Tutorial: Software Risk Management, IEEE Press, 1989, pp. 495.

(C) Mottonen et al.; Licensee Bentham Open.

This is an open access article distributed under the terms of the Creative Commons Attribution License (http://creativecommons.org/licenses/by/2.5/), which permits unrestrictive use, distribution, and reproduction in any medium, provided the original work is properly cited. 